\title{
Estudo comparativo de eletrodos comerciais para soldagem subaquática molhada
}

\author{
(Comparative study of commercial electrodes for underwater wet welding)
}

\begin{abstract}
Alexandre Q. Bracarense1, Ezequiel C. Pessoa2, Valter R. dos Santos 3, Maurício J. Monteiro3, Fernando C. Rizzo3, Sidnei Paciornik3, Ricardo Reppold4, José R. Domingues5, Leonardo A. Vieira5

1Departmentode Engenharia Mecânica, UFMG, Minas Gerais, Brasil,bracarense@ ufmg.br, 2Instituto Federal de Enducação Tecnologica - IFET-MG, Gerais, Brasil ecpp76@gmail.com, 3Department of Materials Science and Metallurgy, PUC-Rio, Rio de Janeiro,Brasil,valtersa@esp.puc-rio.bre mauricio@puc-rio.br,4PETROBRAS/CENPES, Rio de Janeiro, Brasil, reppold@petrobras. com.br, 5ESAB Soldagem e Corte, Minas Gerais, Brasil
\end{abstract}

\begin{abstract}
Resumo
Com o objetivo de fornecer subsídios para a seleção de consumíveis para a soldagem molhada foram determinadas algumas propriedades do metal de solda a partir de juntas soldadas em água doce com eletrodos revestidos comerciais específicos para este fim. As soldas foram realizadas em tanque a 0,5m de profundidade por dispositivo de soldagem por gravidade. Foram levantados dados que auxiliem a eleger os consumiveis de melhor desempenho para serem testados em maiores profundidades. Foram realizados os seguintes testes e avaliações: caracterização microestrutural, análise e quantificação das inclusões, composição química do metal de solda, dureza Vickers, hidrogênio difusível e avaliação da soldabilidade. Os resultados obtidos permitem classificar os consumíveis testados em dois grupos com características bem distintas. No primeiro grupo está o único eletrodo do tipo oxidante e no segundo grupo estão os quatro eletrodos do tipo rutílico testados. Quanto às propriedades mecânicas e às características operacionais, os eletrodos do tipo rutílico apresentaram os melhores resultados. Por outro lado, o eletrodo oxidante testado produziu soldas com mais baixo teor de hidrogênio difusível e, portanto, menor risco potencial de provocar trincas a frio. As diferenças de propriedades entre os eletrodos testados são evidenciadas e discutidas no presente trabalho.
\end{abstract}

Palavras-chave: Soldagem molhada, soldagem subaquática, eletrodos revestidos, metal de solda, microestrutura, propriedades mecânicas, estabilidade de arco, características operacionais, hidrogênio difusível.

Abstract: With the objective to supply subsidies to select ferritic electrodes for underwater wet welding, some weld metal characteristics of commercial electrodes were determined. The welding trials were carried out at $0.5 \mathrm{~m}$ fresh water depth in an aquarium, using a gravity device for welding. The study aimed also to obtain data to help to elect the consumables of best performance to be tested in higher depths. The following characterizations were performed: microstructural analysis, quantification of inclusions, weld metal and inclusions chemical composition, mechanical properties, diffusible hydrogen and weldability evaluation. The obtained results helped to classify the tested consumables in two groups with quite different characteristics. The first group is composed of one oxidizing type electrode and the second one is composed of four rutile type electrodes. Regarding to hydrogen in the weld metal, the obtained results show that the oxidizing electrode is able to produce welds with considerable low diffusible hydrogen content. As a consequence, smaller potential risk of cold cracking is expected when using this electrode. Meantime, regarding to the arc stability and other operational indicators, the oxidizing electrode presented inferior performance. Considering mechanical properties, the rutile electrodes presented the best results. The properties differences among the electrodes tested are shown and discussed in the present work.

Key-words: Wet welding, underwater welding, covered electrodes, weld metal, microstructure, mechanical properties, arc stability, operational characteristics, diffusible hydrogen.

\section{Introdução}

Apesar de numerosos esforços de pesquisa e desenvolvimento para melhorar as propriedades de soldas molhadas, a soldagem com eletrodos revestidos, em contato

(Recebido em 02/09/2010; Texto final em 30/11/2009). Artigo originalmente publicado no CONSOLDA 2009, Piracicaba, SP, Outubro de 2009. direto com a água, ainda apresenta problemas não resolvidos que implicam em sérias dificuldades na obtenção de juntas soldadas com qualidade estrutural plena ou semelhante à qualidade atingida em juntas soldadas nas condições atmosféricas [1-8]. Por outro lado importantes progressos têm sido feitos quanto à melhoria das propriedades mecânicas do metal de solda. A literatura técnica [9] e fabricantes de consumíveis reportam a possibilidade de conseguir, sob certas condições, propriedades trativas e de impacto no metal de solda suficientes para qualificar procedimentos de soldagem molhada com qualidade estrutural. Em soldagem subaquática usualmente referencia-se a norma 
D3.6M:1999 da AWS [10], onde as soldas estruturais são classificadas em duas categorias. Para as soldas tipo A estão presentes requisitos de tenacidade, resistência, dutilidade, dureza e dobramento em níveis semelhantes aos exigidos pelos principais códigos de engenharia em soldagem atmosférica. Para as soldas tipo B, conceituadas como soldas com qualidade estrutural limitada, tanto os testes aplicados na qualificação de procedimentos quanto os critérios de aceitação são menos rigorosos que os referentes ao tipo A. Vários documentos [2, 6] relatam resultados de testes de juntas soldadas que mostram a possibilidade de qualificar procedimentos de soldagem molhada no tipo B da referida norma AWS.

A elevada velocidade de resfriamento resultante da ação refrigerante da água durante a soldagem impõe algumas características microestruturais à zona afetada pelo calor (ZAC) do metal de base que se constituem em importantes barreiras à obtenção de soldas tipo A. São geradas na ZAC microestruturas de elevada dureza, acima do patamar de dureza máxima exigida para soldas tipo A. Adicionalmente, estas regiões de elevada dureza apresentam baixa tenacidade e estabelecem variações abruptas de dureza entre metal de solda e ZAC, diminuindo a dutilidade e, conseqüentemente, a capacidade de deformação em testes de dobramento. A conjunção dos fatores mencionados, notadamente a elevada dureza na HAZ e a elevada quantidade de hidrogênio difusível $\left(\mathrm{H}_{\text {dif }}\right)$ no metal de solda, pode levar à formação de trincas por hidrogênio. $\mathrm{O}$ aumento da porosidade com a profundidade [1] também contribui bastante para a diminuição da dutilidade e é um dos fatores reponsáveis pela reprovação no teste de tração "all weld", requerido pela classe A.

Outro importante aspecto a considerar é a soldabilidade operatória, que no caso da soldagem molhada é extremamente importante pelo fato de que adicionalmente o soldador enfrenta situações ambientais adversas que provocam desconforto e instabilidade. Este problema de instabilidade do arco pode ser diminuindo com a utilização de fontes de soldagem especiais com regulagem eletrônica de corrente [11] para reduzir o número de curtos circuitos. O que acontece, entretanto é que estas fontes nem sempre estão presentes e mesmo que estivessem, considerando o elevado número de estruturas de produção flutuantes sendo atualmente empregadas (navios e plataformas semi-submersíveis) e que podem apresentar sérias restrições de ordem econômica para a docagem para manutenção e reparos, é cada vez mais importante dispor da soldagem molhada como uma técnica aceita pelas sociedades classificadoras e pelas empresas operadoras em trabalhos de reparo estrutural em águas rasas.

A perspectiva de que a soldagem molhada receberá maior importância, considerando as crescentes necessidades futuras de reparos estruturais [13], motivou a realização do presente trabalho cujo objetivo é avaliar os principais eletrodos comerciais para soldagem molhada objetivando, por meio de um conhecimento mais detalhado de suas características, otimizar a seleção de eletrodos para aplicações específicas, pré-qualificar procedimentos de soldagem molhada e estabelecer padrões de referência para o desenvolvimento de novos eletrodos. Objetivase também levantar dados que auxiliem a eleger consumíveis a serem testados em maiores profundidades. Para isolar os efeitos de aumento de pressão e da habilidade do soldador nas propriedades das soldas, este trabalho se restringe à avaliação de soldas realizadas em laboratório, na profundidade de $0,5 \mathrm{~m}$, utilizando dispositivo mecanizado de soldagem por gravidade.

\section{Métodos experimentais}

Os eletrodos revestidos comerciais testados no presente trabalho, disponíveis no mercado nacional e internacional, foram identificados por A, B, C, D e E. Todos os eletrodos possuíam diâmetro da alma de $3,25 \mathrm{~mm}$ e comprimento de $35 \mathrm{~mm}$. Com exceção do eletrodo A, os demais são fornecidos com revestimento impermeabilizado cuja formulação e técnicas de aplicação não são reveladas pelos fabricantes. Os eletrodos do tipo A foram revestidos com verniz vinílico em espessura suficiente para permitir mantê-los imersos durante a preparação e a realização da soldagem sem considerável absorção de umidade.

Foram soldadas juntas de topo com chanfro em V, depósitos sobre chapa e corpos-de-prova para medição de $\mathrm{H}_{\text {dif }}$. Todas as soldas foram realizadas em água doce, na profundidade de $0,5 \mathrm{~m}$, por gravidade (arraste), na posição plana e eletrodo com ângulo de $60^{\circ}$. Foi empregada uma fonte eletrônica de corrente constante com corrente nominal CC+ de $160 \mathrm{~A}$. As soldas forma monitoradas por um sistema de aquisição de dados de tensão e corrente com alta taxa de aquisição 1000 pontos por segundo. A figura 1 ilustra o sistema de soldagem molhada empregado. As chapas usadas foram de aço ASTM A-36 com dimensões de $300 \mathrm{~mm}$ por $300 \mathrm{~mm}$ com espessura de $16 \mathrm{~mm}$ preparadas com chanfro em $\mathrm{V}$ de $60^{\circ}$. Para as caracterizações metalográfica, química, e de propriedades mecânicas foram soldadas com cada tipo de eletrodo 2 (duas) juntas com abertura de raiz de $3 \mathrm{~mm}$. Foi empregado cobre-junta de aço ASTM A-36 de $5 \mathrm{~mm}$ de espessura.

Foram realizados os seguintes testes e avaliações, dirigidos exclusivamente para o metal de solda:

- Análise macrográfica e caracterização microestrutural por microscopia ótica;

- Determinação da composição química do metal de solda por espectrometria de emissão ótica;

- Determinação do teor de hidrogênio difusível;

- Quantificação e análise química das inclusões por microscopia eletrônica de varredura;

- Medição de dureza Vickers com carga de $1 \mathrm{~kg}$;

- Ensaios de tração transversal e de tração do metal de solda;

- Ensaio de impacto Charpy em corpos de prova removidos transversalmente ao cordão de solda a $0^{\circ} \mathrm{C}$;

- Avaliação da soldabilidade por indicadores de aspecto, de geometria de cordão e de estabilidade do arco elétrico.

A medição do hidrogênio difusível foi realizada por cromatografia Gasosa em analisador OERLIKON - Yanaco Mod. G1006, segundo as normas AWS A4.3; ASTM E260 e E355. Os resultados apresentados são a média de no mínimo, três medições próximas. Os parâmetros operacionais empregados foram idênticos aos adotados na soldagem das juntas de topo.

A preparação metalográfica das amostras foi realizada 
segundo as técnicas de polimento e ataque convencionais. As quantidades de região colunar $(\mathrm{CR})$, reaquecida de grãos grosseiros (CGR) e reaquecida de grãos finos (FGR) do metal de solda foram medidas com magnificação de 50x, em seção transversal, ao longo de uma linha de $10 \mathrm{~mm}$ de comprimento, perpendicular à superfície da chapa, localizada no centro do cordão de solda. As quantidades relativas dos microconstituintes da região colunar foram determinadas por contagem de pontos, pela aplicação de uma grade de 100 pontos sobre imagens com magnificação de 500x. O tamanho de grão na FGR foi determinado pelo método de interseções com magnificação de 500x.

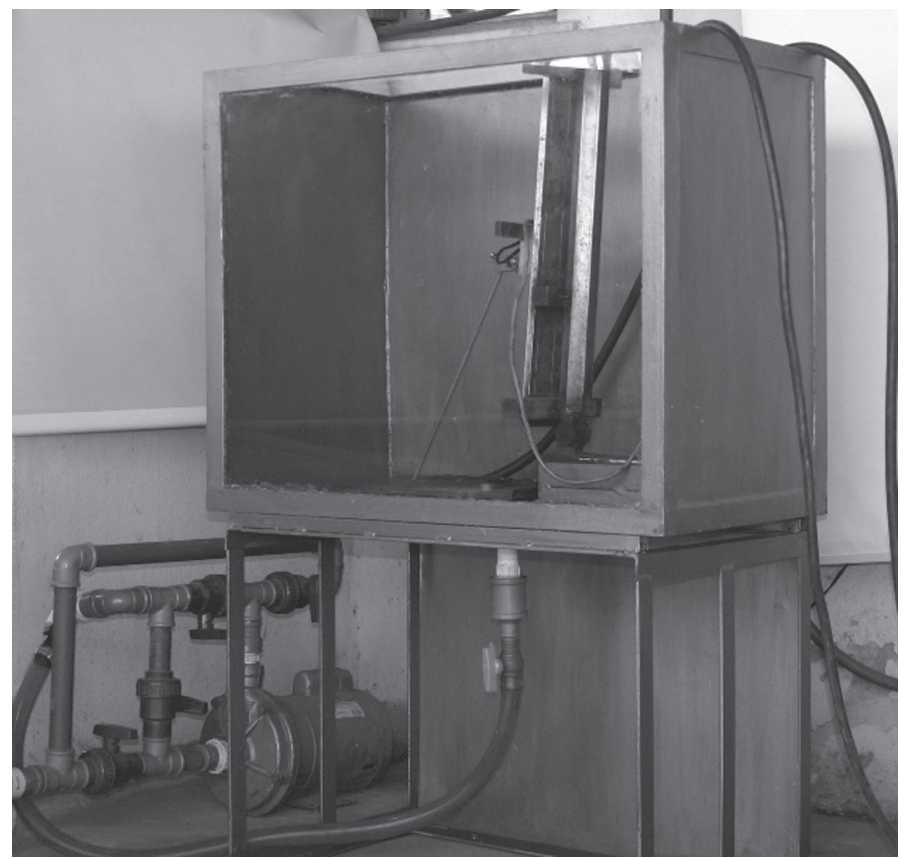

Figura 1. Sistema de soldagem

Para determinação do tamanho, da quantidade e da fração de área de inclusões foram obtidas imagens de 30 campos por elétrons retroespalhados (BSE) com 4.000x de aumento. A determinação da composição química das inclusões foi determinada por EDS em no mínimo 6 inclusões com diâmetro entre $4 \mu \mathrm{m}$ e $8 \mu \mathrm{m}$.

A medição de dureza foi realizada em três seções transversais por meio de 10 endentações ao longo de uma linha de $10 \mathrm{~mm}$ de comprimento, perpendicular à superfície da chapa e localizada no centro do cordão de solda.

Os ensaios de tração transversal e de tração do metal de solda foram conduzidos de acordo com a norma D3.6M:1999 da AWS. Excepcionalmente foram empregados corpos-de-prova não padronizados em ensaios de tração transversal quando a ruptura ocorreu no metal de base nos ensaios padronizados. As dimensões (em mm) de tais corpos-de-prova não padronizados são apresentadas na figura 2 .

Para a avaliação da soldabilidade foram depositados cinco (5) cordões de solda sobre chapa para cada eletrodo nas mesmas condições adotadas na soldagem das juntas de topo. Os dados de corrente, tensão e tempo de soldagem foram obtidos na freqüência de aquisição de $1.000 \mathrm{~Hz}$ durante toda a soldagem. Para o tratamento dos dados relativos a cada eletrodo foram selecionados três cordões de solda e em cada um deles selecionou-se um intervalo de 5 segundos (entre o $10^{\circ}$ e o $15^{\circ}$ segundo). Selecionaram-se assim 5.000 pontos para cada cordão de solda analisado e, para esse intervalo, foram calculados os seguintes parâmetros: $\mathrm{I}_{\text {med }}$ (corrente média), $\mathrm{V}_{\text {med }}$ (tensão média), $\mathrm{S}$ (índice de estabilidade do arco), NCC (número indicativo de curtos-circuitos) e V (velocidade média de soldagem). $\mathrm{O}$ índice de estabilidade do arco adotado foi definido por Madatov [12]. Assim, a estabilidade do arco (S) foi definida como o valor máximo da corrente (Imax) dividido pelo seu valor mínimo (Imin). Os valores de $\mathrm{S}$ devem o mais próximo possível de 1,0 para boa estabilidade de arco; Por outro lado, $\mathrm{S}>>1,0$ indica arco instável. Os cálculos referentes a $\mathrm{I}_{\text {med }}, \mathrm{V}_{\text {med }}$, e NCC foram feitos usando funções do software Excel.

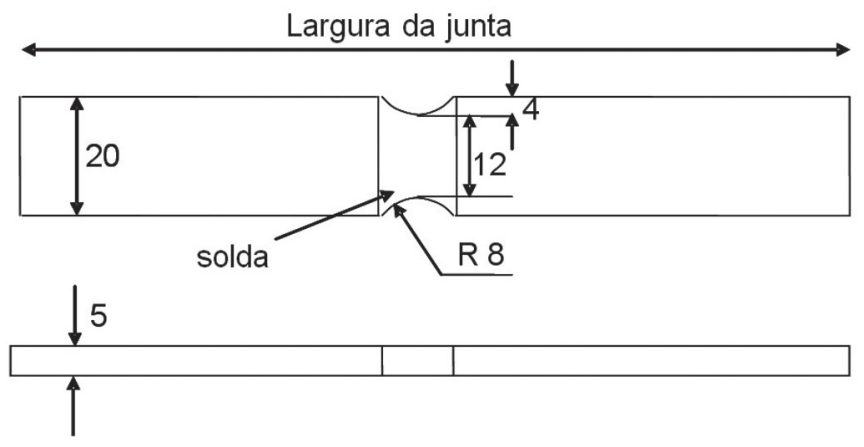

Figura 2. Corpo de prova entalhado para teste de tração transversal (em mm)

Para se calcular os valores de $\mathrm{S}$, utilizou-se o seguinte método: a cada 10 pontos ( 0,01 segundo) de corrente captados, dividiu-se a corrente máxima $\left(\mathrm{I}_{\max }\right)$ pela mínima $\left(\mathrm{I}_{\min }\right)$ obtendose assim, 500 valores de $\mathrm{S}$ para cada cordão. Com esses valores obtidos, calculou-se o $\mathrm{S}$ médio.

Um curto circuito foi definido como qualquer dado de tensão que fosse numericamente inferior a 5 volts. É importante ressaltar que o objetivo não era calcular precisamente o número de curtos-circuitos e sim, obter um parâmetro indicativo de ocorrência dos mesmos para a comparação entre os eletrodos. A velocidade média de soldagem foi determinada através do comprimento do cordão e do tempo de soldagem, usando-se a média dos três cordões.

\section{Resultados e Discussão}

Na tabela 1 são apresentados os resultados de $\mathrm{H}_{\text {dif }}$ obtidos com desvio padrão (STD). Os valores relativos aos eletrodos B, C, D e E são próximos e bastante elevados. Por outro lado o eletrodo A apresenta um resultado bem inferior, evidenciando pertencer a uma classe distinta dos demais.

A figura 3 apresenta a macrografia, em seção transversal, da junta soldada com o eletrodo C (escolhido como exemplo). Nesta figura a área tracejada indica a região onde foram realizadas a caracterização microestrutural, a analise das inclusões e as medições de dureza. 
Tabela 1. Resultados de hidrogênio difusível dos eletrodos testados

\begin{tabular}{|c|c|c|c|c|c|c|}
\hline Eletrodo & \multicolumn{4}{|c|}{$\mathrm{H}_{\mathrm{dif}}(\mathrm{ml} / 100 \mathrm{~g})$} & Média & STD \\
\hline A & 18,7 & 24,5 & 18,1 & - & 20,43 & 3,53 \\
\hline $\mathrm{E}$ & 98,8 & 101,4 & 91,4 & - & 97,20 & 5,19 \\
\hline $\mathrm{D}$ & 96,8 & 100,9 & 68,5 & - & 88,73 & 17,64 \\
\hline $\mathrm{B}$ & 84,8 & 87,8 & 89,7 & - & 87,43 & 2,47 \\
\hline $\mathrm{C}$ & 85,1 & 105,2 & 72,3 & 78,9 & 85,38 & 14,21 \\
\hline
\end{tabular}

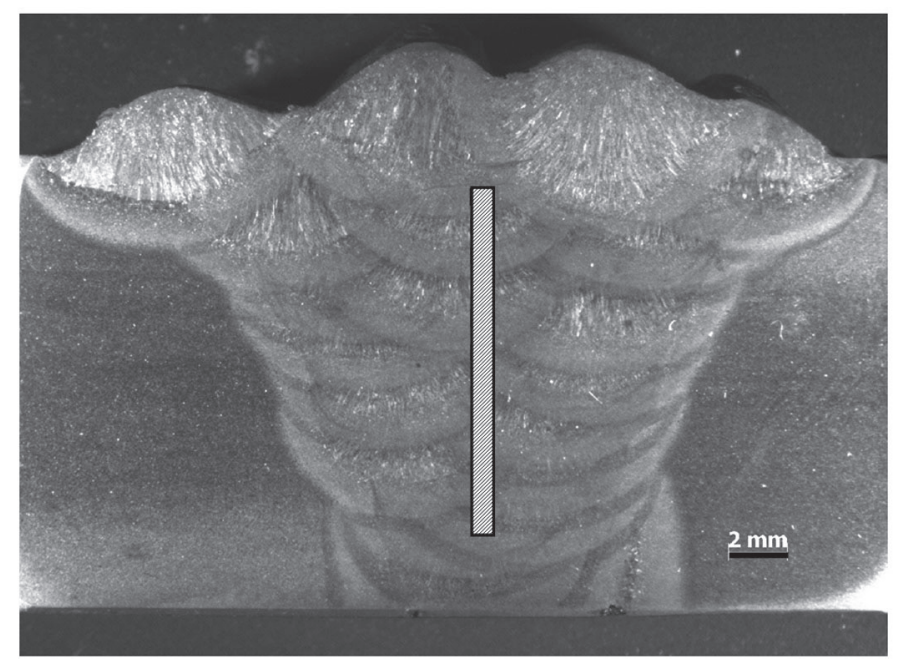

Figura 3. Aspecto típico da solda em chanfro produzida (eletrodo C).

Na figura 4 podem ser visualizadas as microestruturas típicas do metal de solda (WM) e da região reaquecida de grãos finos (FGR). Não são apresentadas as microestruturas da região reaquecida de grãos grosseiros (CGR) que, pela sua pequena participação na composição do metal de solda, adquire menor importância. Nas microestruturas do metal de solda observouse:

- Presença de ferrita acicular (AF) somente na RC relativa aos eletrodos B, C e D;

- Presença de ferrita pró-eutetóide (PF) e ferrita com segundas fases alinhadas (FSF) na RC relativa a todos os eletrodos;
- Presença de agregados ferrita-carbetos (FCA) dispostos ao longo dos contornos de grão da austenita prévia exclusivamente na $\mathrm{RC}$ relativa ao eletrodo $\mathrm{D}$;

- Presença de ferrita poligonal na RGF relativa a todos os eletrodos;

- Presença de ferrita acicular na RGF relativa aos eletrodos B, C e D

- De uma forma geral, as microestruturas dos metais de solda relativos aos eletrodos B e C são semelhantes.

A tabela 2 apresenta os resultados das análises quantitativas da estrutura do metal de solda. Destaca-se o fato de que a maior parte do metal de solda é formada pela região de grãos finos, a qual deverá ser a principal responsável pelas propriedades mecânicas do metal de solda. Observa-se que as regiões colunares do metal de solda dos eletrodos B, C e D possuem quantidades consideráveis de ferrita acicular que contribuirão positivamente no sentido de melhorar a tenacidade.

$\mathrm{Na}$ figura 5 são apresentados os resultados da análise metalográfica quantitativa das inclusões na forma de diagramas de caixa. Diagrama de caixa ("Box plots"). O diagrama apresenta a média, os valores máximo e mínimo, bem como os 25, 50 . (mediana) e 75 percentis. Os bigodes ("whiskers") representam os valores entre 5 e 95 percentis. Pode ser observado para o eletrodo A que, tanto a fração volumétrica de inclusões quanto a quantidade de inclusões são superiores aos dos demais eletrodos. Observa-se que os resultados referentes aos eletrodos B, C, D e E são bastante próximos. Os diâmetros médios das inclusões situaram-se muito próximos para todos os eletrodos. O menor valor médio foi $0,48 \mu \mathrm{m}$ para o eletrodo $\mathrm{C}$ e $0,55 \mu \mathrm{m}$ para o eletrodo A.

Tabela 2. Resultado quantitativo da estrutura metalográfica de regiões do metal de solda dos eletrodos testados.

\begin{tabular}{|c|c|c|c|c|c|c|c|}
\hline Eletrodo & RC\% & RGG\% & RGF\% & AF\% & PF\% & FSF\% & ${\text { FGS }(\mu \mathrm{m})^{\mathrm{a}}}$ \\
\hline A & 15,3 & 11,3 & 73,3 & 1,0 & 49,0 & 50,0 & 4,02 \\
\hline B & 35,0 & 19,0 & 46,0 & 40,6 & 33,2 & 26,2 & 3,85 \\
\hline C & 35,0 & 21,0 & 44,0 & 37,4 & 29,4 & 33,2 & 3,92 \\
\hline D & 21,0 & 26,5 & 52,5 & 42,2 & 8,4 & 49,4 & 3,08 \\
\hline E & 24,0 & 20,0 & 56,0 & 4,6 & 45,0 & 50,4 & 3,85 \\
\hline
\end{tabular}

${ }^{a}$ tamanho de grão ferrítico mínimo na região de grãos finos

Obs: FCA não foi considerado 

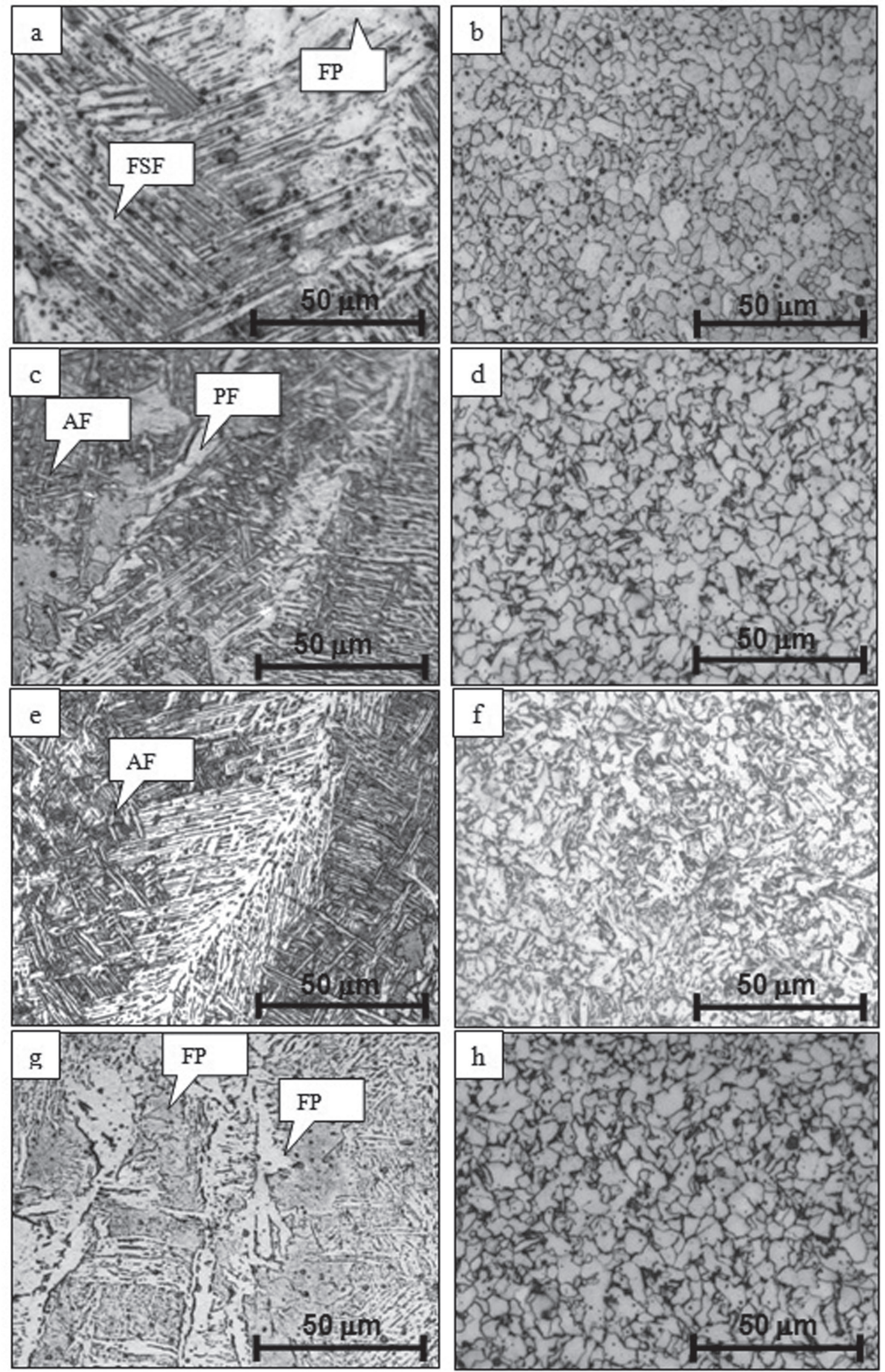

Figura 4. Microestruturas típicas da região colunar (esquerda) e região de grãos finos reaquecida (direita). (a) e (b): eletrodo A. (c) e (d): eletrodos B e C. (e) e (f): eletrodo D. (g) e (h): eletrodo E. 


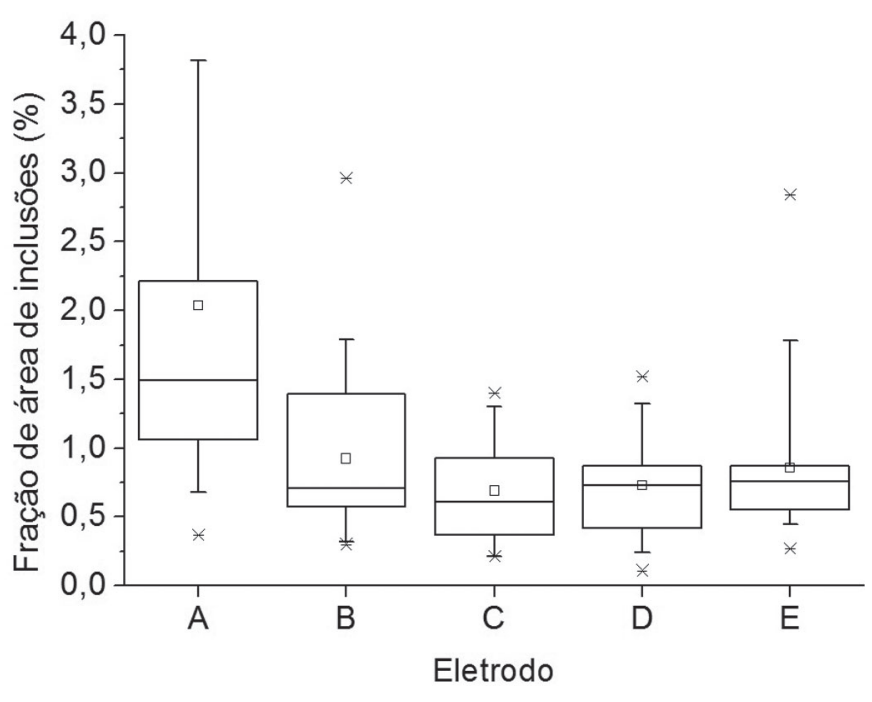

Fig. 5a. Fração de área de inclusões

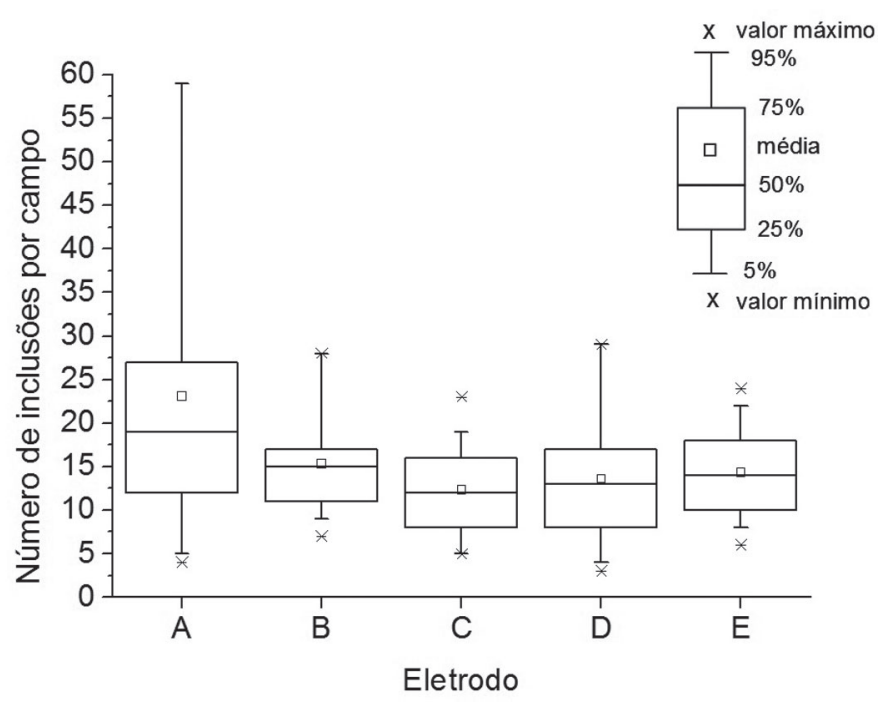

Fig. 5b. Quantidade de inclusões.

Os resultados de composição química do metal de solda e das inclusões são apresentados nas tabelas 3 e 4, respectivamente. Observa-se que o eletrodo A apresenta composição química bem distinta dos demais. Durante o processo de transferência metálica que compreende fusão da ponta do eletrodo, formação de gotas, transporte das gotas e formação e resfriamento da poça de fusão, o excesso de oxigênio livre reage com os elementos desoxidantes, notadamente o silício e o manganês, reduzindo-os a níveis extremamente baixos (da ordem de 0,01 e 0,037, respectivamente, conforme a tabela 3 ). Outras evidências do elevado potencial de oxidação do eletrodo A são as características das inclusões nãometálicas. Estas estão presentes em maior quantidade e são ricas em óxido de ferro, como se depreende da figura 5 e da tabela 4 , respectivamente. A grande quantidade de inclusões e os baixos teores de Si e Mn propiciam a formação de microconstituintes de baixa resistência e tenacidade, conforme mostrado na tabela 2 e tendem a reduzir as propriedades relacionadas à resistência mecânica tais como limite de escoamento e de resistência à tração, dureza e tenacidade, coerentemente com os resultados apresentados na tabela 5. No eletrodo $\mathrm{A}$, a redução de tais propriedades mecânicas é parcialmente compensada pela adição de aproximadamente $2 \%$ níquel (tabela 3 ), cuja principal função é reduzir o tamanho de grão da região reaquecida. Observa-se na tabela 2 que o tamanho de grão de grão ferrítico na região reaquecida de grãos finos aproxima-se do resultado obtido para os demais eletrodos. A grande oferta de oxigênio livre no sistema traz, entretanto, um importante benefício que é a obtenção de baixo teor de hidrogênio difusível no metal de solda (tabela 1), cuja explicação pode estar associada à maior pressão parcial do oxigênio na bolha de vapor que envolve o arco elétrico ou nas propriedades físicas e químicas da escória. Os mecanismos de redução do hidrogênio difusível relativamente aos eletrodos do tipo oxidante em soldagem molhada não são ainda perfeitamente compreendidos e sua discussão não é objeto do presente trabalho.

Apesar da grande dispersão ocorrida nos resultados de composição química das inclusões, fica evidenciada a diferença de composição do eletrodo A em relação aos demais, coerentemente com os resultados de composição do metal de solda da tabela 3 . No eletrodo A as inclusões são formadas predominantemente de óxidos de ferro e quantidades pequenas de óxidos de manganês e silício. Tal fato indica um caráter fortemente oxidante deste eletrodo. As composições das inclusões dos demais eletrodos são típicas de eletrodos rutílicos e as variações entre elas não podem ser consideradas expressivas.

Os eletrodos B, C, D e E são eletrodos do tipo rutílico, conforme informado por alguns dos respectivos fabricantes. A diferença mais acentuada entre eles é a presença de Mo como elemento de liga no eletrodo D. De fato o conjunto de suas características metalográficas, composições químicas e propriedades mecânicas, obtidas no presente trabalho, correspondem àquelas de eletrodos com importante participação de óxido de titânio no revestimento. A análise das características levantadas mostra que eles se comportam de forma semelhante, com algumas diferenças pouco significativas. Todos depositam metal de solda com próximos e elevadíssimos teores de hidrogênio difusível o que os torna mais suscetíveis à formação de trincas de hidrogênio tanto na zona afetada pelo calor quanto no metal de solda. As microestruturas da região colunar do metal de solda, com exceção do eletrodo E, contêm ferrita acicular em teores da ordem de $40 \%$, o que explica os elevados valores de propriedades mecânicas, em geral, a ponto de permitir sua classificação como E70XX. Uma diferenciação relevante entre eles é a presença de molibdênio no metal de solda do eletrodo $\mathrm{D}$, que resulta em microestrutura mais rica em ferrita acicular, com presença de agregados ferrita-carbetos e o menor tamanho de grão na região reaquecida de grãos finos dentre todos os eletrodos. Em consequiência o eletrodo D apresentou os maiores valores dureza. 
Tabela 3. Composição do metal de solda (porcentagem em peso)

\begin{tabular}{|c|c|c|c|c|c|c|c|c|c|c|c|}
\hline Eletrodo & $\mathrm{Mn}$ & $\mathrm{Si}$ & $\mathrm{Ti}$ & $\mathrm{P}$ & $\mathrm{S}$ & $\mathrm{C}$ & $\mathrm{Ni}$ & $\mathrm{Cr}$ & $\mathrm{V}$ & $\mathrm{Cu}$ & $\mathrm{Mo}$ \\
\hline $\mathrm{A}$ & 0,033 & 0,010 & 0,000 & 0,015 & 0,007 & 0,055 & 2,020 & 0,000 & 0,000 & 0,034 & 0,000 \\
\hline $\mathrm{B}$ & 0,501 & 0,309 & 0,018 & 0,020 & 0,012 & 0,087 & 0,055 & 0,054 & 0,019 & 0,119 & 0,000 \\
\hline $\mathrm{C}$ & 0,513 & 0,384 & 0,015 & 0,014 & 0,009 & 0,070 & 0,069 & 0,051 & 0,017 & 0,044 & 0,000 \\
\hline $\mathrm{D}$ & 0,609 & 0,370 & 0,013 & 0,025 & 0,008 & 0,075 & 0,036 & 0,027 & 0,024 & 0,020 & 0,440 \\
\hline $\mathrm{E}$ & 0,343 & 0,199 & 0,011 & 0,026 & 0,007 & 0,090 & 0,026 & 0,014 & 0,013 & 0,024 & 0,000 \\
\hline
\end{tabular}

Tabela 4. Composição química de inclusões (porcentagem em peso)

\begin{tabular}{|c|c|c|c|c|c|c|}
\hline Eletrodo & $\mathrm{Fe}$ & $\mathrm{Mn}$ & $\mathrm{Si}$ & $\mathrm{Ti}$ & $\mathrm{O}$ & $\mathrm{Al}$ \\
\hline $\mathrm{A}$ & 55,8 & 7,3 & 8,5 & 0,0 & 28,3 & 0,0 \\
\hline $\mathrm{B}$ & 5,2 & 28,0 & 15,3 & 11,2 & 37,2 & 1,6 \\
\hline $\mathrm{C}$ & 11,8 & 24,1 & 15,7 & 11,9 & 36,4 & 0,1 \\
\hline $\mathrm{D}$ & 14,2 & 24,8 & 17,5 & 7,4 & 36,1 & 0,0 \\
\hline $\mathrm{E}$ & 12,5 & 20,7 & 20,7 & 7,3 & 38,3 & 0,1 \\
\hline
\end{tabular}

Tabela 5. Propriedades mecânicas do metal de solda

\begin{tabular}{|c|c|c|c|c|c|c|c|}
\hline Eletrodo & $\begin{array}{l}\text { Dureza } \\
(\mathrm{HV} 1)^{\mathrm{a}}\end{array}$ & L.E. (Mpa) & $\begin{array}{l}\text { L.R. } \\
(\mathrm{Mpa})^{\mathrm{b}}\end{array}$ & $\begin{array}{l}\text { Along. } \\
(\%)^{\mathrm{b}}\end{array}$ & $\begin{array}{c}\text { Estricção } \\
(\%)^{\mathrm{b}}\end{array}$ & $\begin{array}{c}\text { Tensão de } \\
\text { rutura }(\mathrm{Mpa})^{\mathrm{c}}\end{array}$ & $\begin{array}{l}\text { Charpy V } \\
0^{\circ} \mathrm{C}(\mathrm{J})^{\mathrm{d}}\end{array}$ \\
\hline A & 183,5 & 379 & 456 & 24,0 & 45,0 & 469 & 33,6 \\
\hline B & 201,9 & 325 & 522 & 6,6 & 6,0 & 617 & 37,6 \\
\hline $\mathrm{C}$ & 200,2 & 354 & 464 & 2,4 & 17,0 & 640 & 47,7 \\
\hline $\mathrm{D}$ & 220,6 & 362 & 513 & 6,0 & 4,1 & $>631^{\mathrm{e}}$ & 40,5 \\
\hline E & 183,0 & 375 & 515 & 11,0 & 15,4 & 603 & 39,2 \\
\hline
\end{tabular}

a: Média de 30 identações, b: Tração do metal de solda sendo 1 (um) ensaio para os eletrodos A, B, C e E e 2 (dois) ensaios para o eletrodo D, c: Ensaio de tração transversal sendo uma média de 2 (dois) ensaios para os eletrodos B, C e E e somente 1 (um) ensaio para os eletrodos A e D, d: Média de 3 ensaios, e: Ruptura no metal de base

Os resultados dos ensaios de dureza Vickers, Charpy, tração transversal e de tração do metal de solda são resumidos na tabela 5. Comparando-se as propriedades de todos os eletrodos observa-se que o eletrodo A claramente diferencia-se dos demais por baixos valores de dureza e resistência mecânica e apresenta resultados inferiores, porém próximos, para a tenacidade. Por outro lado, apresenta ductilidade muito superior aos demais. Comparando-se os eletrodos B, C, D e E observa-se que suas propriedades mecânicas apresentam diferenças pouco significativas entre si.

Os baixos valores de alongamento no ensaio de tração do metal de solda motivaram uma observação um pouco mais aprofundada quanto à existência de descontinuidades internas que pudessem resultar em perda de dutilidade sob direção de aplicação de carga paralela à direção longitudinal do cordão de solda. As macrografias transversais ao cordão de solda não indicaram presença de descontinuidades. Entretanto, nas micrografias em seção transversal com magnificação de 500x, foram observadas algumas microtrincas. Novas amostras metalográficas foram preparadas, agora em seção longitudinal. Trincas foram observadas, mesmo sob baixa magnificação nos metais de solda dos eletrodos B, C, D e E, conforme ilustrado na figura 6. A influência das pequenas trincas transversais no metal de solda pode ser melhor entendida considerando-se a figura 7, que corresponde à observação em MEV do corpo-de-prova de tração do metal de solda do eletrodo $\mathrm{D}$, o qual apresentou alongamento de $4 \%$. A figura 7 a mostra trincas em degraus na superfície lateral do corpo-de-prova, fáceis de observar até mesmo a olho nu. Estas trincas são o resultado da abertura e interligação de pequenas trincas transversais preexistentes no metal de solda. A figura 7(a) mostra a superfície da fratura do corpo-de-prova onde são observados alguns platôs, cujas superfícies correspondem às trincas transversais preexistentes. A morfologia das superfícies dos platôs, representada na figura 7c, tem aspecto dendrítico, de possível ocorrência em trincas de hidrogênio. A área que envolve os platôs, mostrada na figura 7d, é formada por microcavidades (aspecto esperado para fraturas dúteis no metal de solda) 

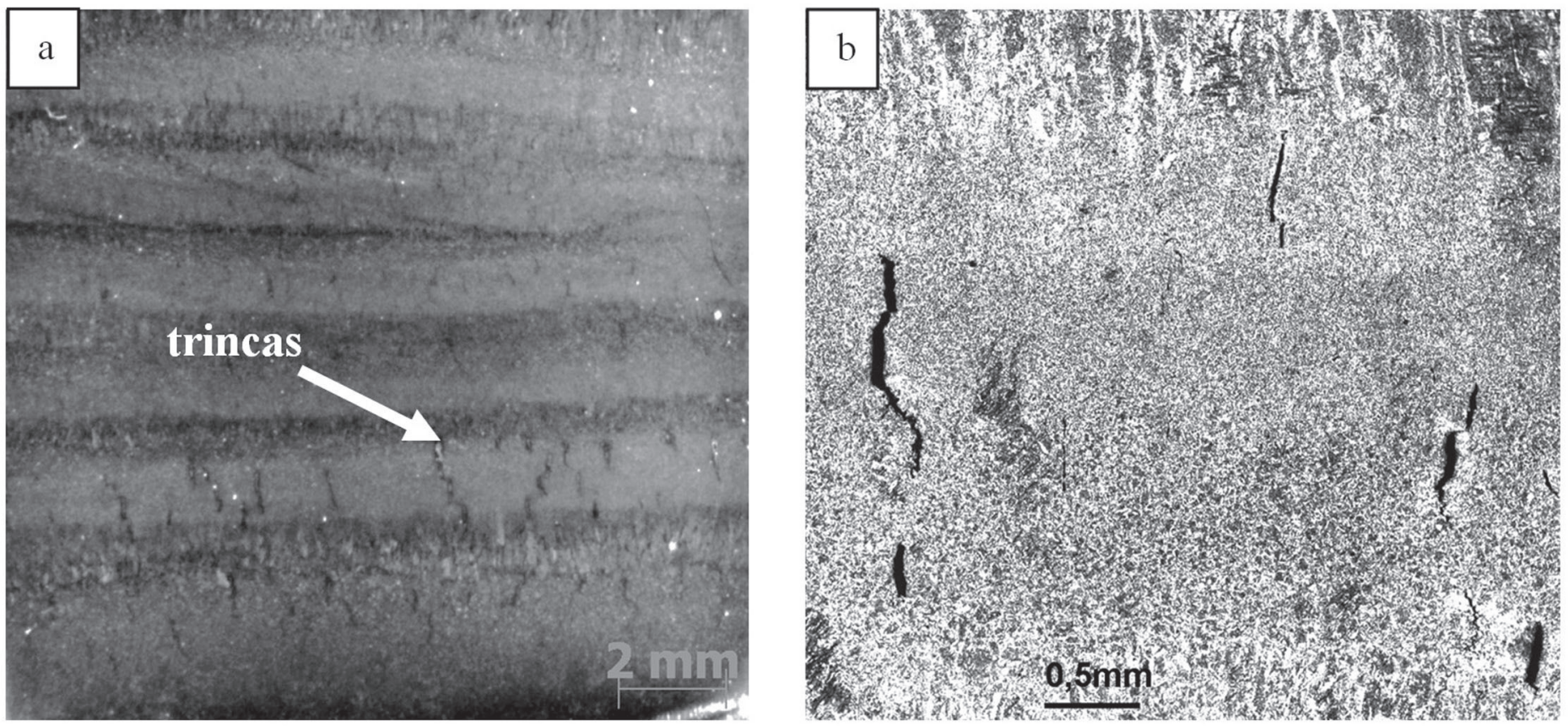

Fig. 6. Exemplo de trincas transversais em seção longitudinal do metal de solda dos eletrodos B, C, D e E. a) Eletrodo D, nital 2\%, magnificação nominal: 5x. b) Eletrodo B, nital 2\%, magnificação nominal: 50x

É sabido que procedimentos de soldagem molhada em pequenas profundidades (até $30 \mathrm{~m}$ ) têm sido qualificados [13] segundo a norma AWS D3.6M:1999 classe B (estrutural limitada). Entretanto, quando o objetivo é a qualificação de soldas em chanfro na classe A (estrutural plena) não se tem conhecimento de iniciativas bem sucedidas. Para a classe A, a referida norma exige a realização do ensaio de tração do metal de solda cujo critério de aceitação para o alongamento é de um valor mínimo de $14 \%, 16 \%, 18 \%$ ou $20 \%$, a depender do diâmetro do corpode-prova empregado e do limite de resistência à tração do metal de solda. Cabe observar da dificuldade de se obter valores de alongamento superiores a $10 \%$ neste tipo de ensaio. Os resultados dos ensaios de tração do metal de solda e os exames macro e micrográficos realizados no presente trabalho acrescentam dados importantes para analisar esta questão. Para todos os eletrodos do tipo rutílico o alongamento foi significativamente inferior ao mínimo especificado, embora as demais propriedades mecânicas incluindo a tenacidade, medida pelo ensaio Charpy, tenham sido satisfatórias. Observa-se, ainda, que para os mesmos eletrodos o limite de resistência à tração na direção longitudinal é inferior á mesma propriedade da direção transversal ao cordão de solda. Outro dado importante a considerar é que, em geral, os valores das propriedades mecânicas semelhantes aos usualmente obtidos na soldagem atmosférica com eletrodos rutílicos convencionais, à exceção do alongamento, cujo valor típico é superior a $20 \%$. Por outro lado, foi obtido um valor do alongamento de $24 \%$ relativo ao eletrodo A, apesar da grande quantidade de inclusões no seu metal de solda. Fica evidente que a explicação está na presença ou não de trincas de hidrogênio transversais no metal de solda. As normas de soldagem em geral, incluindo a de soldagem subaquática AWS D3.6M:1999 prevêem a realização de exame macrográfico em seção transversal na qualificação de procedimentos e o critério de aceitação é a não observação de trincas sob magnificação de $5 x$. Nestas condições pequenas trincas transversais não são aparentes. Como as maiores tensões residuais no cordão de solda são as longitudinais é previsível que as trincas de hidrogênio se situem em planos perpendiculares à direção do eixo do cordão de solda. De fato, as observações de seções longitudinais e de superfícies de fratura, conforme ilustrado nas figuras 6 e 7 evidenciaram a presença de numerosas trincas para os eletrodos B, C, D e E (alto $\mathrm{H}_{\text {dif }}$ ) e ausência de trincas para o eletrodo A. Tais resultados indicam que a redução do hidrogênio difusível dos eletrodos do tipo rutílico é fundamental para evitar a presença de trincas de hidrogênio do metal de solda e atingir valores de ductilidade especificados para conseguir a qualificação na classe A da norma AWS D3.6M:1999. Além disso, a realização de ensaio de impacto com o entalhe aberto transversalmente a direção de soldagem e exame macrográfico em seção longitudinal, se incluídos nos processos de qualificação, poderiam detectar o a presença das trincas transversais no metal de solda.

Deve ser enfatizado que os resultados do presente trabalho estão limitados ao comportamento da soldagem molhada sob pressão muito próxima da atmosférica. $\mathrm{O}$ aumento da profundidade terá influências tanto nas propriedades químicas, na porosidade e nas propriedades mecânicas do metal de solda assim como no comportamento do arco elétrico e conseqüentemente na estabilidade do arco. Em decorrência, está prevista a continuidade deste estudo por meio da realização de testes e análises comparativas em soldas executadas sob maiores pressões empregando eletrodos comerciais. 

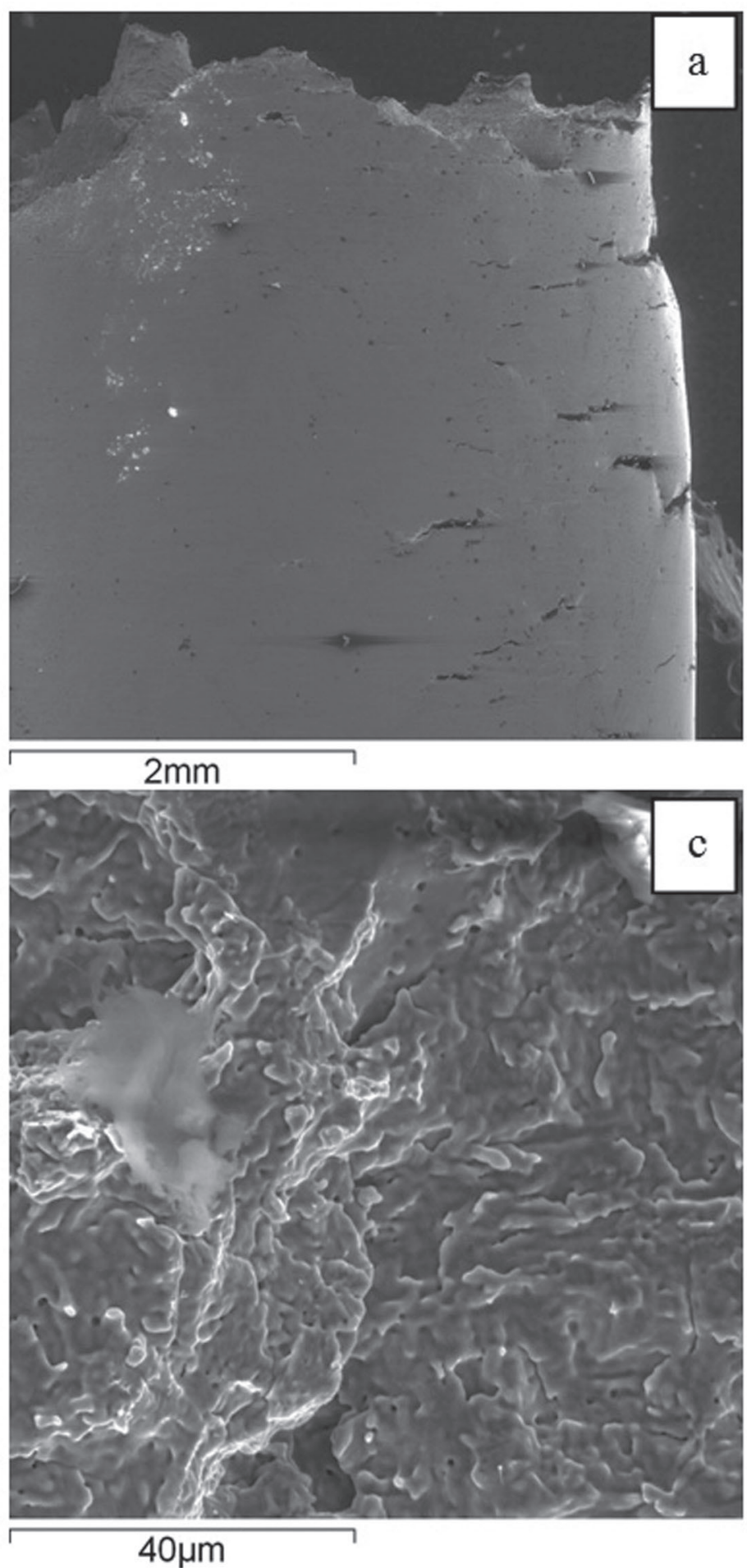
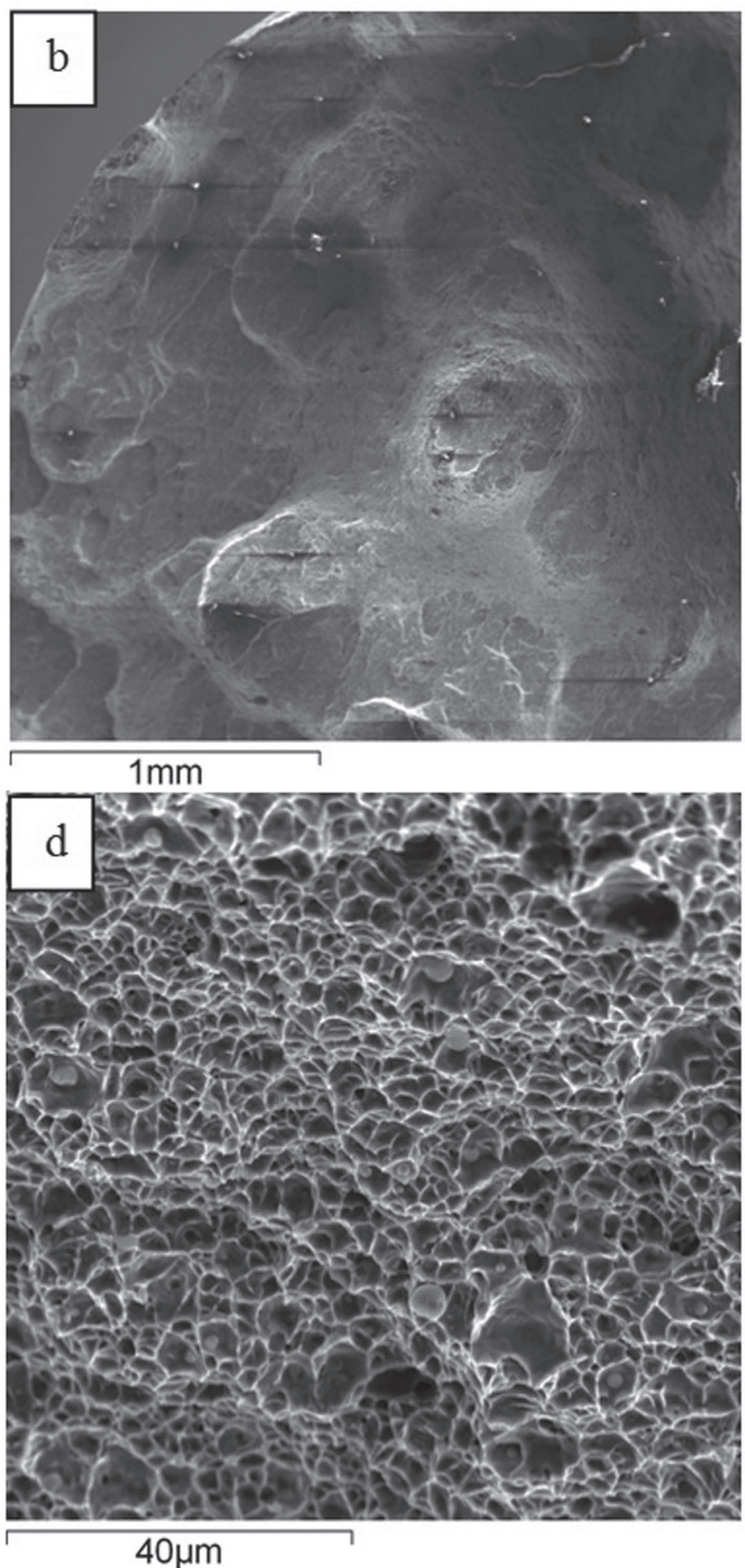

Fig. 7. Morfologia da fratura no corpo-de-prova de tração do metal de solda em MEV. a) superfície lateral apresentando inúmeras trincas em degrau. b) superfície da fratura apresentando platôs. c) superfície dos platôs apresentando aspecto dendrítico. d) Aspecto dominante da superfície da fratura apresentando microcavidades.

\subsection{Características operacionais}

Em relação a soldabilidade, observou-se que os eletrodos B, C, D e E apresentaram melhores resultados do que o eletrodo A. Em geral esses quatro eletrodos apresentaram maior facilidade de abertura e melhor manutenção de arco elétrico, escória mais facilmente removível e um melhor aspecto geral do cordão. Os eletrodos B, C, D e E produziram melhores soldas com velocidades de soldagem menores (ângulo do eletrodo em torno de $70^{\circ}$ ), enquanto que o eletrodo $\mathrm{A}$, produziu melhores resultados com velocidades de soldagem maiores (ângulo do eletrodo em torno de $60^{\circ}$ e velocidade de soldagem em torno 


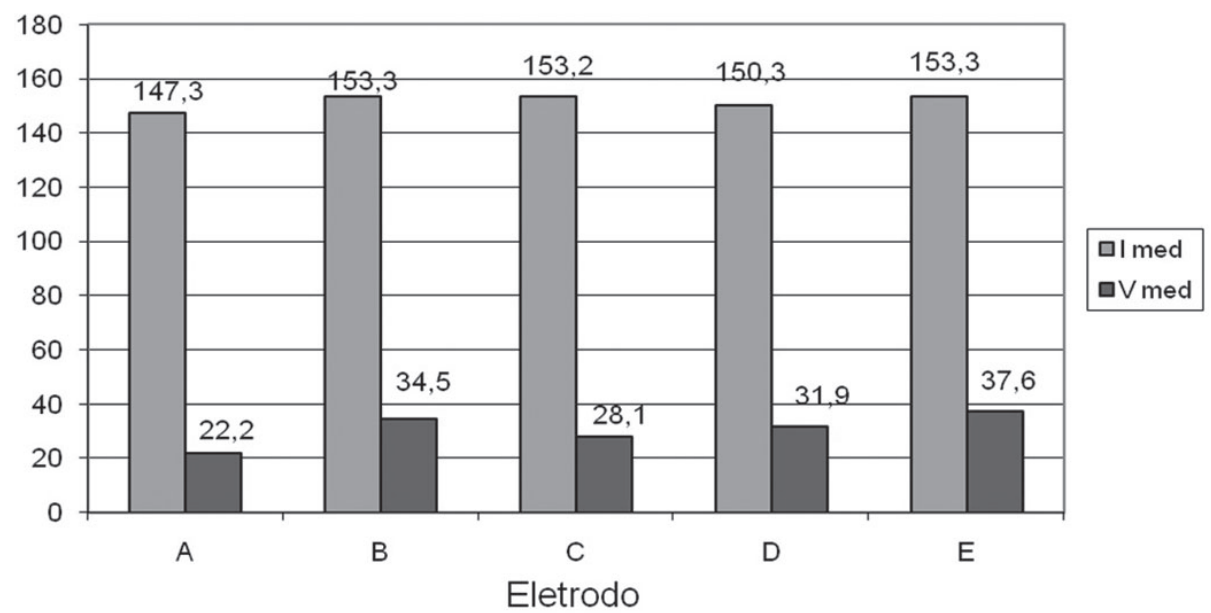

Figura 8 - Valores de corrente e tensão médios adquiridos durante a realização dos depósitos sobre chapa

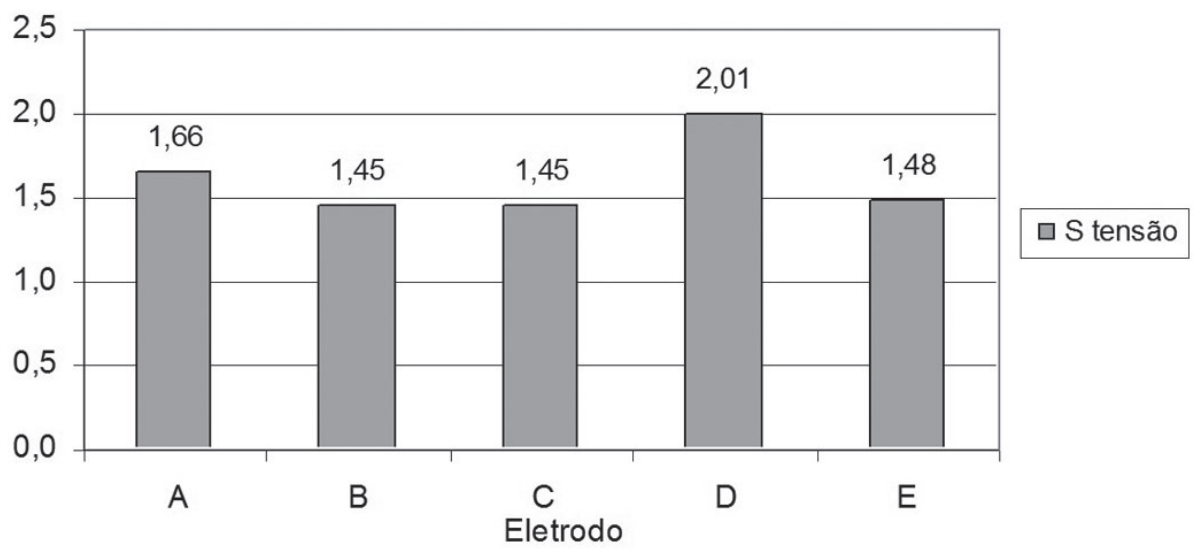

Figura 9 - Parâmetro de estabilidade S da tensão para os eletrodos testados

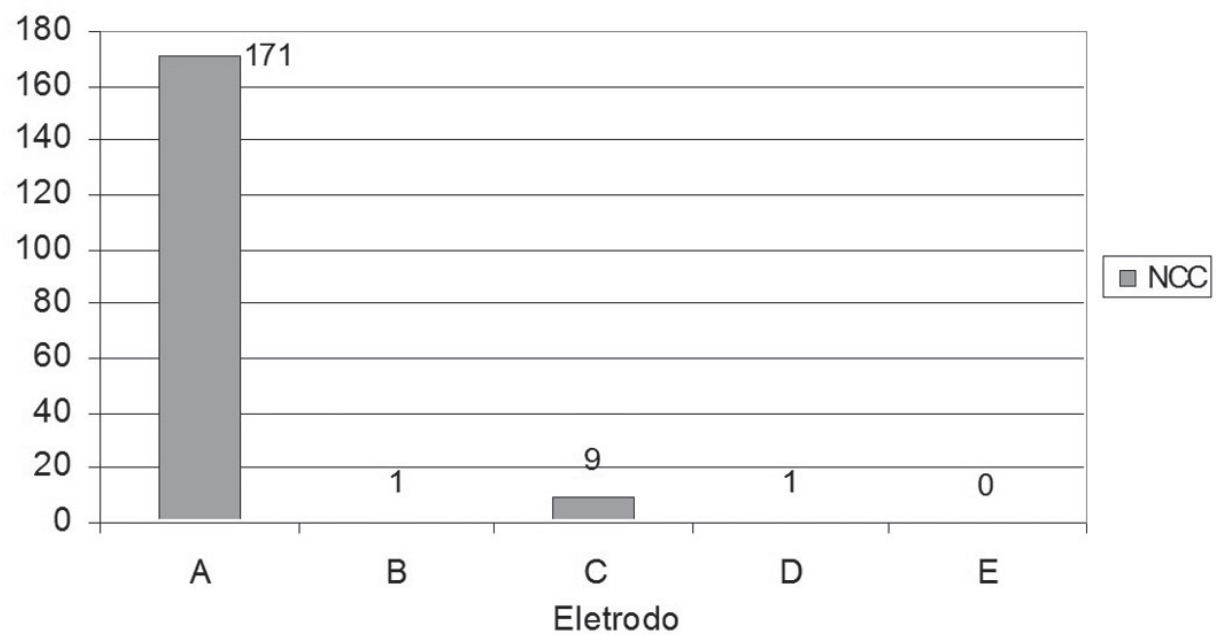

Figura 10 - Número de curtos circuitos medidos nos depósitos sobre chapa

de $3,0 \mathrm{~mm} / \mathrm{s})$. Em altas velocidades os eletrodos B, C, D e E apresentam mordeduras.

Os resultados da análise dos dados de corrente e tensão adquiridos estão mostrados nos gráficos das Figuras 8 a 10.
Os resultados obtidos na análise dos sinais de corrente e tensão mostraram os eletrodos B, C, D apresentaram tensão de soldagem próxima de 30 volts enquanto o eletrodo $\mathrm{E}$ tem tensão mais alta e o eletrodo A tensão bem mais baixa. Como 
a tensão de arco está diretamente relacionada ao comprimento do arco elétrico, este aspecto mostrou ser o mais influente nessa análise. Observou-se claramente que os eletrodos B, C D e E apresentaram quase ausência de curto-circuito, menor diferença entre a corrente ajustada na máquina (160 A) e a corrente média medida. Tendo como base o parâmetro de estabilidade do arco (S) da tensão, os eletrodos B, C e E apresentaram valores mais próximos de 1 (ou seja, mais estáveis).

Embora não tenha havido diferenças significativas na largura dos cordões, observou-se que os eletrodos B, C, D e E produziram cordões com maior penetração, com valores próximos a 4,0 mm, superiores em mais de duas vezes aos valores apresentados pelo eletrodo A.

\section{Conclusões}

Considerando composição química do metal de solda, composição química e parâmetros morfométricos das inclusões e propriedades mecânicas, os resultados obtidos permitem classificar os consumíveis testados em dois grupos com características bem distintas. No primeiro grupo está o eletrodo do tipo oxidante (A) e no segundo grupo estão os quatro eletrodos do tipo rutílico (B, C, D e E).

As propriedades mecânicas relacionadas à resistência e à tenacidade do metal de solda dos eletrodos do tipo rutílico mostraram-se próximas entre si e superiores à do eletrodo oxidante. A maior fração volumétrica de inclusões, o maior tamanho de grão na região reaquecida do metal de solda e a ausência de ferrita acicular na microestrutura são os principais fatores responsáveis.

Os resultados dos ensaios de tração do metal de solda mostraram que os eletrodos do tipo rutílico são anisotrópicos em relação ao alongamento e à resistência mecânica. A existência de trincas de hidrogênio transversais nos metais de solda dos eletrodos do tipo rutílico induz perda de resistência e de dutilidade quando a direção do esforço é longitudinal em relação ao cordão de solda.

Quanto aos teores de hidrogênio difusível os resultados obtidos mostram que eletrodo oxidante testado é capaz de produzir soldas com baixo teor e, portanto, menos suscetíveis à ocorrência de trincas a frio, tanto no metal de solda como na ZAC do metal de base.

Os eletrodos rutílicos apresentaram arco mais estável, menor número de curtos-circuitos, maior penetração e melhores características operatórias em geral.

\section{Agradecimentos}

Os autores agradecem à PETROBRAS e à ESAB S.A pelo financiamento deste projeto, à PUC-Rio/DCMM/ITUC e à UFMG/LRSS.

\section{Referências:}

[1] CHRISTENSEN N. The Metallurgy of MMA Hyperbaric Welding, SINTEF report No. STF34 F83032, Trondheim, 1983. [2] GOOCH, T. G. Properties of Underwater Welds. Part 1.
Procedures Trials. Metal Construction, pp.164-167,vol.8, March, England, 1983.

[3] IBARRA, S., GRUPPS, C. E., LIU, S. State-of-the-Art and Practice of Underwater Wet Welding of Steel, Proceedings: Internationaal Workshop on Underwater Welding of Marine Structures. New Orleans, Lousiana.pp 49-67, 1994.

[4] IBARRA, S., REED, R. L., SMITH, J. K., PACHNIUK, I., GRUPPS, C. Underwater Wet Welding Repair of an Offshore Platform in the North Sea. Proceedings of the First International Offshore and Polar Engineering Conference. Edinburgh, UK, 11-16 august, 339-346, 1991.

[5] IBARRA, S.; GRUBBS, C., E.; OLSON, D., L. Metallurgical aspects of underwater welding. Journal of Metals. Vol. 40, no. 12, pp. 8-10. Dec. 1988 apud ANDRADE, L. P. C. da SILVA. Soldagem Subaquática Molhada com Eletrodo Tubular. Programa de Pós-Graduação em Engenharia Mecânica, Florianópolis, Santa Catarina: Universidade Federal de Santa Catarina, Dissertação, 124f, 1995.

[6] LIU, S., OLSON, D. L., IBARRA, S., Electrode Formulation to Reduce Weld Metal Hydrogen and Porosity, proceedings: $13^{\text {th }}$ Offshore Mechanics and Arctic Engineering Conference. Copenhagen, Denmark. OMAE- 1994, pp 291-298, 1994b.

[7] LIU, S., POPE, A. M., and DAEMEN, R. Welding Consumables and Weldability, International Workshop on Underwater Welding of Marine Structures, Lousiana, USA, pp.321-350, 1994a.

[8] POPE, A.M., LIU, S., TEIXEIRA, J.C.G., dos SANTOS, V.R., PAES, M.T.P. Use of Nickel to Improve the Mechanical Properties of High Oxygen Underwater Wet Welds, OMAE Materials Engineering, Volume III, pp. 102-117, American Society of Mechanical Engineering (ASME), August, USA, 1995a.

[9] POPE, A. M. Oxygen and Hydrogen Control in Shielded Metal Underwater Wet Welding, Metallurgical and Materials Engineering Department, Colorado School of Mines, Golden, Colorado, EUA, Tese, 156f, 1995.

[10] AMERICAN WELDING SOCIETY. Specification for Underwater Welding, ANSI/AWS D3.6M:1999.

[11] OLlÉ, L., LEAL, A., BAIXO, C., DUTRA, J., POPE, A. e TEIXEIRA, J. C. G, Desenvolvimento de Metodologias Aplicadas ao Controle da Corrente na Soldagem a Arco em Ambiente Molhado, XXV Encontro Nacional de Tecnologia da Soldagem, Minas Gerais, Brasil, 1999.

[12] MAZZAFERRO, J. A. E., Estudo da Estabilidade do Arco Elétrico na Soldagem Subaquática com Eletrodos Revestidos. Universidade Federal do Rio Grande do Sul. Brasil, Tese, 1998. [13] MARINHO, M.G., POPE, A.M., MENICONI, L.C., ALVES, L.H.M., DELVECHIO, C., (2005). Integrity Assessment and On-Site Repair of a Floating Production Platform . 24th International Conference on Offshore Mechanics and Arctic Engineering - OMAE, paper 67504, Halkidiki, Greece, 2005. 